\title{
Psychosocial support interventions for improved adherence and retention in ART care for young people living with HIV (10-24 years): a scoping review
}

\author{
Emeka F. Okonji ${ }^{*}$ D, Ferdinand C. Mukumbang(D, Zaida Orth (B), Shelley A. Vickerman-Delport and Brian Van Wyk(D)
}

\begin{abstract}
Background: Mental health disorders such as high levels of anxiety, isolation, depression and suicide ideation reported among young people living with HIV (10-24 years; YPLHIV) contribute significantly to poor medication adherence and retention in care. While there is evidence supporting the role of psychosocial support interventions in promoting adherence and retention in antiretroviral treatment (ART) among adults living with HIV, there is little evidence on the role of psychosocial support on medication adherence among YPLHIV. This scoping review was designed to identify and classify the types and effects of psychosocial support interventions designed to improve adherence and retention in ART among YPLHIV globally.

Method: We searched six electronic databases (i.e., Scopus, Pubmed and EBSCOHost (Academic Search Premier, CINAHL, Psycarticles and Medline). Six relevant articles published between 2011 and 2019 met our inclusion criteria. We extracted information relevant to the nature and outcomes of the reported interventions using thematic content analysis informed by the Population, Intervention, comparison, outcome, and time (PICOT) framework.

Results: Four distinctive treatment modalities that focused on improving ART adherence and retention in care were identified: individual counselling, support groups, family-centered services, and treatment supporters.

Conclusion: There is a dearth of psychosocial support interventions to improve adherence and retention in ART amongst adolescents and young adults living with HIV. Future research and programming should seek to address psychosocial support interventions or approaches specifically designed to address the needs of YPLHIV.
\end{abstract}

Trial registration: PROSPERO: Registration CRD42018105057.

Keywords: Adolescents, Psychosocial support, Interventions, HIV and AIDS, Adherence and retention

* Correspondence: emekaokonji@yahoo.com

School of Public Health, University of the Western Cape, P Bag X17, Bellville,

Cape Town 7535, South Africa

(c) The Author(s). 2020 Open Access This article is licensed under a Creative Commons Attribution 4.0 International License, which permits use, sharing, adaptation, distribution and reproduction in any medium or format, as long as you give appropriate credit to the original author(s) and the source, provide a link to the Creative Commons licence, and indicate if changes were made. The images or other third party material in this article are included in the article's Creative Commons licence, unless indicated otherwise in a credit line to the material. If material is not included in the article's Creative Commons licence and your intended use is not permitted by statutory regulation or exceeds the permitted use, you will need to obtain permission directly from the copyright holder. To view a copy of this licence, visit http://creativecommons.org/licenses/by/4.0/. The Creative Commons Public Domain Dedication waiver (http://creativecommons.org/publicdomain/zero/1.0/) applies to the data made available in this article, unless otherwise stated in a credit line to the data. 


\section{Background}

Since the introduction of antiretroviral therapy (ART), significant gains have been made in mitigating the impact of the HIV/AIDS pandemic [1]. The increasing effectiveness of and access to ART, along with increasing innovations in ART service delivery have redefined the HIV epidemic from a deadly infectious disease to a chronic, manageable disease [1-3]. However, poor adherence to treatment and suboptimal retention in care continue to present significant challenges to ending AIDS by 2030 [4].

In 2018, UNAIDS estimated that 1.6 million young people aged 10-24 years were living with HIV [5, 6]. Therefore, young people living with HIV (YPLHIV) constitute a growing and key sub-population of people living with HIV globally. The increasing availability and effectiveness of ART worldwide has resulted in more children and adolescents living longer with $\mathrm{HIV}[7,8]$. However, it is welldocumented that adolescents struggle to initiate, remain engaged, and consistently adhere to ART $[9,10]$. While most of the individual, social and health systems barriers associated with ART adherence and retention in care affecting the general population also apply to YPLWH, the latter face greater risks of mental and behavioural health problems, which constitute additional barriers [7, 11, 12]. Psychological risk factors such as anxiety and depressive disorders result from the chronicity of HIV infection, being orphaned, changes of guardianship, and the nature of parental and other adult support [11, 13, 14].

Due to the high levels of anxiety, isolation, depression and suicide ideation reported among YPLWH, studies have recommended psychosocial support for YPLWH in addition to standard ART services to help them adapt and cope with the chronicity and stigma associated with $\operatorname{HIV}[3,11,12,15-17]$. Psychosocial support interventions are interpersonal or informational activities, strategies or techniques that can target biological, behavioural, cognitive, emotional, interpersonal, social or environmental factors with the aim of improving an individual's health functioning and mental well-being [18]. To promote ART adherence and retention in care among YPLWH, a comprehensive psychosocial intervention is needed. Such psychosocial support interventions should promote HIV disclosure and communication, support adherence to medication, address feelings of isolation and other emotional-related distress, and the needs associated with emerging sexuality [19, 20].

Interventions such as counselling, cognitive behavioural therapy, and peer support have been applied to improve the mental health and overall well-being of people living with HIV over 18 years with success [21], supporting the role of psychosocial support interventions in promoting adherence and retention in ART care among adults living with HIV [22]. Nevertheless, there is little evidence on the nature and role of psychosocial support for YPLHIV [23]. To this end, in this review, we sought to identify, classify and assess the types and effects of psychosocial support interventions focused on improving adherence and retention in care among YPLHIV on ART in the current existing literature.

\section{Method}

Our scoping review was conducted in line with the guidelines proposed by Khan et al. [24] i.e. (1) Framing the question; (2) Identifying relevant publications; (3) Assessing study quality; (4) Summarising the evidence; and (5) Interpreting the findings.

Based on the literature, we developed Boolean phrases that were tested using PubMed. The first literature search was conducted between March and October 2018. Due to unforeseen delays, an updated search using the same Boolean phrases and databases was conducted between October 2019 to March 2020. We searched multiple electronic databases - Scopus, PubMed and EBSCOHost (Academic Search Premier, CINAHL, Psycarticles and Medline) using a standard Boolean combination: "((adolescen* OR teenage* OR young people OR youth) [AND] (psychosocial intervention) [AND] (adherence in antiretroviral therapy OR retention in care))". In addition, we hand-searched grey literature on mental health among YPLWH and transitioning YPLWH from paediatric to adult care. All titles and abstracts (including conference abstracts) were independently screened by SAV and ZO using the PICOT (Participants, Interventions, Comparisons, Outcomes and Time) mnemonics criteria described in Table 1. Discrepancies were resolved via discussions with a third researcher (FCM). Full texts of potentially relevant articles were retrieved and independently examined by the authors. The reference lists of considered relevant articles were also hand searched to identify further potentially relevant studies. Summaries of the interventions described in each article were retrieved using a standardized form, and key information such as study purpose, nature of intervention described, outcome of intervention and conclusions of each study were extracted.

The acronym PICOT informed the eligibility criteria for inclusion in the scoping review: the population (participants) of focus, types of interventions (and comparisons), and the outcomes of interest. The time relates to the period within which the studies were published [see Table 1 below].

Studies were considered eligible for inclusion in this scoping review if they met the following criteria: (i) Evaluated the effects of or associations between psychosocial support intervention and adherence ART or retention in care or related biomedical outcomes e.g., viral 
Table 1 PICOT based inclusion criteria

\begin{tabular}{|c|c|}
\hline Patient population & Adolescents or young adults (10-24 years) living with HIV \\
\hline Intervention of Interest & Psychosocial support \\
\hline Comparison interventions & None \\
\hline \multicolumn{2}{|l|}{ Outcomes } \\
\hline Primary outcomes & $\begin{array}{l}\text { (1) Adherence to antiretroviral treatment (viral load); } \\
\text { (2) Retention in care }\end{array}$ \\
\hline Secondary outcomes & $\begin{array}{l}\text { (1) Quality of life and wellbeing; } \\
\text { (2) Stigma and discrimination; } \\
\text { (3) Disclosure }\end{array}$ \\
\hline Time & $2005-2020$ \\
\hline \multicolumn{2}{|l|}{ Other considerations } \\
\hline Language & English \\
\hline
\end{tabular}

suppression (primary outcomes). (ii) Reported quantitative measures of the primary outcomes. (iii) Targeted or included samples of YPLHIV (10-24) in a mixed sample. (iv) Was published between January 1, 2005 and March 31, 2020. Only articles published in English were considered. There was no restriction by geographical location.

Studies were excluded if they met the following criteria: (i) Adopted a qualitative research design (ii) Were a study protocol, or any form of review or conference abstracts not developed into full manuscripts. (iii) The population deviated from the age range specified. (iv) The intervention did not target the psychosocial needs of the study population. (v) The intervention focused on HIV prevention.

The quality of the included articles was rated as either "poor", "fair" or "good" by three independent researchers

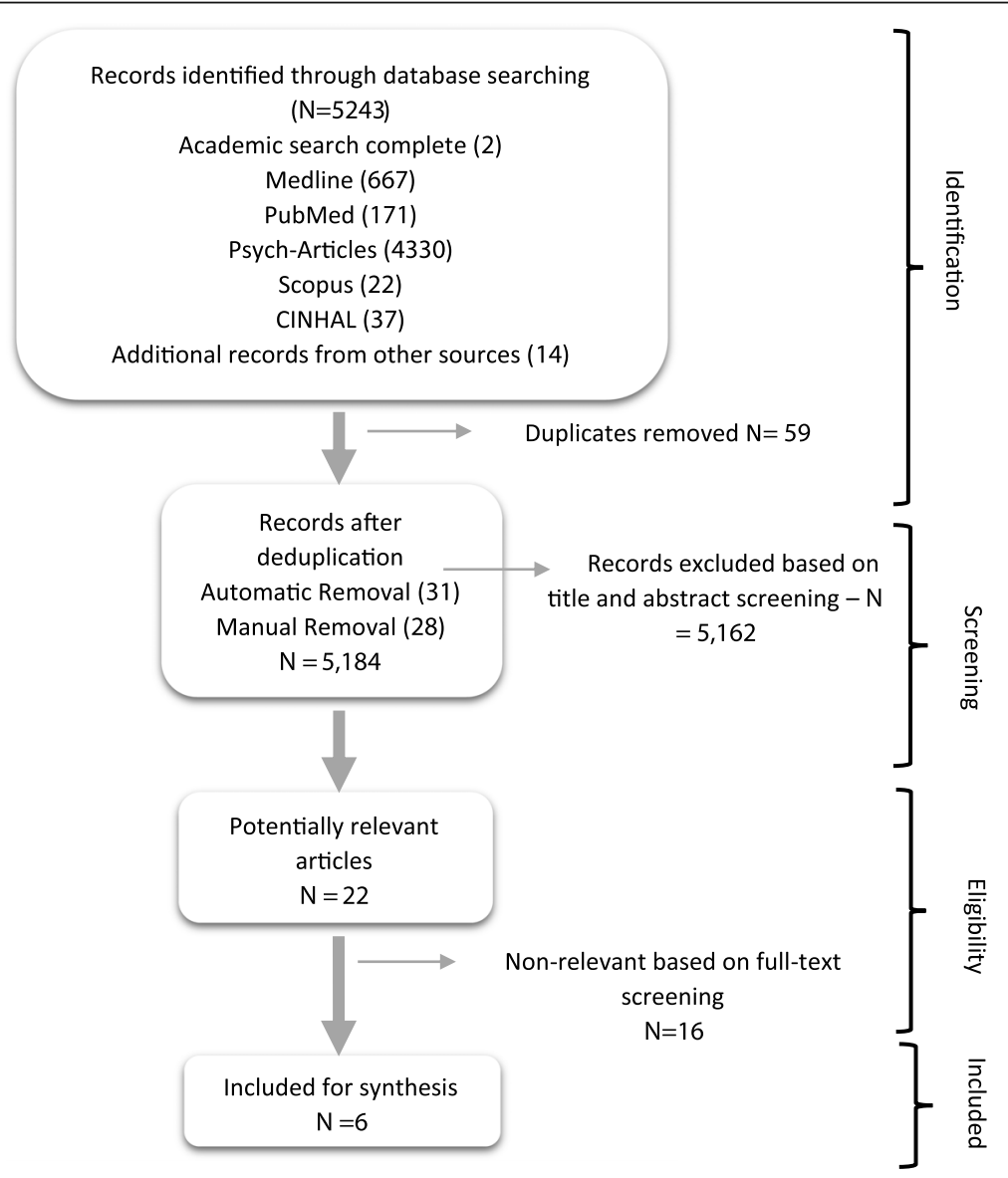

Fig. 1 The PRISMA flow protocol to studies selection 
(EO, SAV and $\mathrm{ZO}$ ), and EO made the final adjudication in cases of non-agreement. The rating of the articles was based on the criteria provided by the NIH-NHLBI Quality Assessment of Systematic Reviews and MetaAnalyses assessment tool [25].

\section{Data extraction}

The data were extracted using an excel spreadsheet under the following headings: study setting, sample characteristics, intervention objectives, study design and methods, outcome measures and results [Additional file 1].

\section{Data analysis}

We employed a thematic content analysis approach to distil information from the selected articles [26]. The extracted information was coded into two broad categories: Intervention components and outcomes measured as informed by the study aim. The intervention components were coded/ classified along the following categories: (1) How the interventions were administered; (2) who delivered the intervention; (3) Point of intervention delivery; and (4) components of the intervention. The outcomes were coded according to the reported primary and secondary outcomes of the study.

\section{Results}

Figure 1 shows the PRISMA diagram illustrating the selection process of the included studies. The literature search resulted in 5244 citations (Fig. 1), which were imported into a reference manager. Electronic (31) and manual (28) deduplication identified 59 duplicates. After screening for potentially relevant titles and abstracts 5162 articles were excluded. After screening full-texts, 17 papers were further excluded because they did not report on the effects of a psychosocial support intervention on adherence and retention in ART for YPLWH. Subsequently, six papers were

Table 2 Characteristics of Included Studies $(N=6)$

\begin{tabular}{lll}
\hline Characteristics & Count & References \\
\hline $\begin{array}{l}\text { Year of Publication } \\
\text { 2011-2015 }\end{array}$ & 3 & {$[27,28,30]$} \\
$2016-2020$ & 3 & {$[29,31,32]$} \\
Country & & \\
$\quad$ United States of America & 2 & {$[28,30]$} \\
Kenya & 1 & {$[29]$} \\
Uganda & 1 & {$[32]$} \\
South Africa & 1 & {$[27]$} \\
$\quad$ Zimbabwe & 1 & {$[31]$} \\
Study design (sample size) & & \\
Pre and post intervention studies $(61 ; 952)$ & 2 & {$[29,30]$} \\
Randomized controlled trial $(4504 ; 66 ; 94)$ & 3 & {$[27,31,32]$} \\
Retrospective cohort (174) & 1 & {$[28]$} \\
\hline
\end{tabular}

included in the review of having good quantitative standards. Five studies were considered to be of good methodological quality [27-31] and one of a fair quality [32].

\section{Characteristics of included studies}

The characteristics of the studies included in the review are summarised in Table 2.

The six papers were disseminated between 2011 and 2019. Two of the studies were conducted in United States of America [28, 30] and four in Southern and Eastern Africa (Uganda, Kenya, South Africa and Zimbabwe) [27, 29, 31, 32]. Two of the papers were preand post-intervention studies $(n=1113)[29,30]$, three randomized control trials (RCT) $[27,31,32](n=4664)$, and one retrospective cohort study $(n=174)$ [28].

\section{Intervention duration}

The duration of study was between 3 months and 10 years [Table 3].

Six studies evaluated psychosocial support interventions, namely: psychosocial education, group adherence counselling, individual counselling and peer-support groups and peer counselling. Two studies evaluated the impact of a family-centred appointment scheduling and health education on patient retention and adherence to monthly appointment scheduling [27, 32]. Three studies evaluated a youth centred management model that combined psychosocial case management, treatment education/adherence support and HIV risk reduction counselling to provide a client-centred intervention through which care was coordinated [28, 30, 31]. Three studies [29, 30,32] evaluated interventions that included fast-track service deliveries to streamline medication pick-up. Table 4 illustrates the nature and characteristics of the interventions identified.

Health and psychosocial education delivered in the form of educational activities and workshops to provide information on HIV and other relevant topics formed an integral part of all six interventions [27-32]. Health education was delivered using posters and cartoons in a structured manner that provided participants with real life situations on navigating through being orphaned by AIDS; moving in with relatives; learning about own HIV diagnosis and treatment needs, while coping with family loss, stigma, peer relationships, identity, and family functioning [27-32]. Furthermore, trained staff who were equipped with the tools to care for and skilled in treating adolescents were employed in six of the interventions e.g. adolescent care providers, youth-focused social workers and psychologist [27-32].

Six studies evaluated interventions that involved individual and peer counselling as part of the interventions [27-32]. The counselling sessions were facilitated by trained community adolescent treatment supporters 
Table 3 Intervention/study location and duration of intervention

\begin{tabular}{|c|c|c|}
\hline Article & Country (location) & Duration of intervention \\
\hline Wohl et al. [30] & USA (Los Angeles) & 2 years \\
\hline Davila et al. [28] & USA (Texas) & $\begin{array}{l}\text { Decentralised era: } 2 \text { years } \\
\text { Centralised area: } 3 \text { years } \\
\text { Enhanced youth services: } 10 \text { years }\end{array}$ \\
\hline Ruria et al. [29] & Kenya (Homa Bay) & 6 months \\
\hline Graves et al. [32] & Uganda & 6 months \\
\hline Bhana et al. [27] & South Africa (KwaZulu-Natal) & 3 months \\
\hline Willis et al. [31] & Zimbabwe (Gokwe south district) & 12 months \\
\hline
\end{tabular}

Table 4 The nature and characteristics of the interventions

\begin{tabular}{|c|c|c|}
\hline Type of intervention & $\mathbf{N}$ & References \\
\hline \multicolumn{3}{|l|}{ Psychosocial education } \\
\hline Teaching/education & 6 & [27-32] \\
\hline Educational workshops & 3 & {$[28,29,32]$} \\
\hline \multicolumn{3}{|l|}{ Adherence counselling } \\
\hline Group counselling/ support groups & 5 & {$[27-29,31,32]$} \\
\hline Individual counselling & 5 & {$[27,29-32]$} \\
\hline \multicolumn{3}{|l|}{ Family centered } \\
\hline Family based psychosocial intervention & 2 & {$[27,32]$} \\
\hline \multicolumn{3}{|l|}{ Fast track/fast lane services } \\
\hline Priority clinic scheduling & 3 & {$[29,30,32]$} \\
\hline \multicolumn{3}{|l|}{ Use of reminder cards/sms } \\
\hline Reminder cards/sms & 1 & {$[32]$} \\
\hline \multicolumn{3}{|l|}{ Intervention agent } \\
\hline Social worker & 2 & {$[28,30]$} \\
\hline Adolescent care provider & 3 & {$[29,31,32]$} \\
\hline Clinical psychologist/Bachelor-level counsellor & 2 & {$[27,30]$} \\
\hline General practitioner/Nurse & 3 & {$[27,29,32]$} \\
\hline Peer counsellor & 4 & {$[28,29,31,32]$} \\
\hline Lay counsellor/CHW & 2 & {$[27,32]$} \\
\hline \multicolumn{3}{|l|}{ Point of intervention delivery } \\
\hline Facility-based & 6 & {$[27-32]$} \\
\hline Community-based & 2 & {$[28,31]$} \\
\hline School-based & 1 & [29] \\
\hline \multicolumn{3}{|l|}{ Components of intervention } \\
\hline Knowledge/education on HIV/AIDS & 6 & [27-32] \\
\hline Adherence to treatment and retention in care & 6 & [27-32] \\
\hline Family-focused programme & 2 & {$[27,32]$} \\
\hline Scheduled visits & 3 & {$[29,30,32]$} \\
\hline Emotional/Affective support & 4 & {$[27,30-32]$} \\
\hline Structural support (youth clinic) & 4 & {$[28,29,31,32]$} \\
\hline Sexual and reproductive health & 5 & [27-31] \\
\hline Disclosure, stigma and discrimination & 5 & {$[27-29,31,32]$} \\
\hline Health promotion & 1 & [32] \\
\hline AIDS related loss and bereavement care & 1 & [27] \\
\hline
\end{tabular}

(CATS), social workers, lay health workers, trained health professionals, or research teams, and aimed to increase HIV knowledge and address adherence and retention barriers [27-32]. These individual counselling methods used a client-centred approach [27, 30-32], or motivational interviewing [28] or peer counselling [29]. Group counselling or support groups were found in five articles as a means of psychosocial support [27-29, 31, 32]. Youth specific support groups addressed issues such as emotional needs; developing self-management skills; capacity building; sexual health; and the stigma related to HIV [28, 31, 32].

One study implemented a school-based programme to create a supportive environment for adherence for YPLWH [29]. The programme offered counselling at schools on sexual and reproductive health and encouraged adolescents to establish health clubs among themselves [29]. In addition, the intervention provided HIV medication on the school premises to enhance adherence and linkage to care, as well supporting participating learners in disclosure [29].

Two of the interventions had family-centred services [27, 32]; with one intervention implementing a family clinic day (FCD) [32]. FCD applied to paediatric and adolescents living with HIV and their immediate family who received priority HIV-care and counselling on a day allocated specifically to them [32]. Another component of FCD was the use of reminder cards and calendars for scheduling appointments. Health education workshops were held, which were led by peers equipped in leading discussions around HIV, sexual and reproductive health, adherence, disclosure, puberty and life skills [27-29, 32]. In addition, the Vuka family programme [27] another family-centred intervention conducted 10 health education workshop sessions that covered subject areas addressing mental and depressive disorders experienced by adolescents living with HIV. These sessions included AIDS-related loss and bereavement, HIV transmission and treatment knowledge; disclosure of HIV status to others; youth identity, acceptance, and coping with HIV; adherence to medical treatment; stigma and discrimination; caregiver child communication, particularly on sensitive topics such as puberty and HIV. The Vuka 
family programme also identified and developed strategies to keep children safe in high-risk situations where sexual behaviour and drug use are common [27]. Furthermore, integrated group sessions were held that were comprised of HIV-infected youth and their caregiver/s, as well as separate group activities for caregivers and preadolescents.

In the case of the Red-Carpet Intervention, adolescents were given VIP express cards- a card offering adolescents fast-track counselling and HIV treatment [29]. One of the interventions also offered adolescents the opportunity to schedule their appointments [32]. Moreover, adolescent waiting areas were implemented to create an adolescent-friendly environment aimed at improving retention to ART services at facilities [28, 32]. Although referral systems were used in two of the programmes, the programmes lacked the services needed by participants, like individual counselling [27]; and support groups for substance abusers; and housing or nutrition services.

Reminders cards and sms were used in one of the studies [32]. Participants were scheduled to attend their next appointment visit using reminder cards and reminded to take their medications by sending SMS messages at regular intervals.

\section{Outcomes measured}

The primary outcomes of interest were adherence to ART and retention in care. The measures of psychosocial support outcomes reported were: (i) selfmanagement (self-efficacy and self-esteem), which is associated with improved self-concept and future orientation [27, 28, 31, 32]; (ii) reduction of stigma and

Table $\mathbf{5}$ Reporting of primary and secondary intervention outcomes

\begin{tabular}{|c|c|c|c|c|c|c|}
\hline \multirow[t]{2}{*}{ Outcomes } & \multicolumn{6}{|c|}{ Studies } \\
\hline & [30] & [32] & [28] & [29] & [27] & [31] \\
\hline Retention in care & $\checkmark$ & $\boldsymbol{x}$ & $\checkmark$ & $\boldsymbol{x}$ & & $\checkmark$ \\
\hline Adherence to medication & & $\checkmark$ & $\boldsymbol{x}$ & $\boldsymbol{x}$ & $\checkmark$ & $\checkmark$ \\
\hline Self-management & & & & & $\checkmark$ & $\checkmark$ \\
\hline Disclosure/Communication & & $\checkmark$ & & & $\checkmark$ & $\checkmark$ \\
\hline Social support & & & & & $\checkmark$ & \\
\hline Instrumental support & $\checkmark$ & & & $\boldsymbol{x}$ & & \\
\hline Family and/or peer support & & $\checkmark$ & & $\boldsymbol{x}$ & & $\checkmark$ \\
\hline Information & & & & $\boldsymbol{x}$ & $\checkmark$ & $\checkmark$ \\
\hline Confidence, self-esteem, self-worth & & & & & & $\checkmark$ \\
\hline \multicolumn{7}{|c|}{$\begin{array}{l}\checkmark: \text { Reported statistical significance } \\
\text { X: No statistical significance } \\
\text { Reference [28] only reported outcomes of retention in care and adherence to } \\
\text { medication and no other psychosocial outcome. Nevertheless, the reference } \\
\text { was included because its intervention included educational activities and } \\
\text { support groups offered by social services staff trained in the use of } \\
\text { motivational interviewing }\end{array}$} \\
\hline
\end{tabular}

discrimination [27, 31]; (iii) disclosure and communication [27, 31, 32]; and (iv) perceived support in the form of social support, instrumental support, family and/or peer support and informational support [28-32]. Our findings showed that five of the studies [28-32] reported on both the primary and secondary intended outcomes [Table 5].

Retention in care was investigated in five of the six studies [28-32]. Three studies found retention in care at 24 months [28], 12 months [31], and 6 months [30] to be significantly higher following exposure to the psychosocial interventions. Wohl et al. [30] found that participants' HIV clinic visits significantly increased between baseline and at 6 months following the youth case management intervention $(p<0.0001)$. Davila et al. [28] found that the centralisation of youth services, which was composed of multifaceted psychosocial intervention components, improved the retention in care of YPLWH $(p<0.01)$ at 12 months. However, there were no significant differences observed in baseline viral load by service era $(p=0.91)[28]$.

Similarly, Ruria et al. [29] conducted a pre- and postintervention to measure retention of YPLWH in ART care. The findings indicated that after 1 month, 90\% of patients were linked to care in the pre-intervention cohort compared to $85.7 \%$ in the post-intervention cohort. The high rate of linkage to care in the pre-intervention phase was attributed to the national policy on Adolescent Reproductive Health and development [29]. However, the results show that following the implementation of the peer counselling and psychosocial support intervention, a significant increase from 66 to $90 \%$; and 54.4 to $98.6 \%$ were observed at 3 months and 6 months respectively. While there is a high rate of YPLWH linking to care within the first month of ART initiation, these numbers dropped with time, and the intervention better success in linking YPLWH to ART over time.

Results from the Family Clinic Day (FCD) intervention showed a significant increase in patient adherence to clinic appointment schedules, that is $65 \%(p<0.01)$ of adolescent participants were adherent to their appointment schedules compared to $53 \%$ participants in the control facilities). However, no effect on retention in care between the control group and the intervention group $(p=0.94)$ was observed [33].

Adherence to medication was reported as a significant outcome in three studies [27, 31, 32]. According to Bhana et al. [27], a self-reported scale on how often medication was missed over the past 6 months by participants in the VUKA intervention reported significantly greater adherence to treatment than those in the control group $(p<0.05)$ [27]. Willis et al. [31] found that the intervention group were 3.9 times more likely to adhere to treatment compared to the control group. 
Four of the studies reported on secondary outcomes [27, 30-32]. The study conducted by Wohl et al. [30] showed that personalised case management interventions provided instrumental support for participants (tangible help provided by others). For example, support in the form of referrals for housing, mental health services, risk reduction education and transportation assistance within the first 6 months post the intervention [30]. Similarly, qualitative findings from the FCD intervention conducted by Graves et al., suggests that the family groups component of the intervention provided participants with increased instrumental, family, peer, and informational support [32]. The findings from the VUKA pilot programme reported significant increases in individual self-concept and future orientation, improved parent-child communication, improved social support and informational support [27]. Furthermore, caregivers reported improved family support, and a decrease in the experience of stigma [27]. One study investigated the effects of community adolescent treatment supporters on psychosocial wellbeing [31]. Willis et al. [31] found a statistically significant increase in confidence, self-esteem and self-worth $(p<0.001)$. In addition, the intervention group reported a statistically significant improvement in the quality of life, while the control group reported a significant decline in the quality of life $(p=0.028)$ [31].

\section{Discussion}

Our review revealed that individual and peer counselling was a distinctive treatment modality when focusing on improving ART adherence, linkage to care and/or retention in care [27-32]. While in two instances, individual counselling was carried out using client-centred theory [30] and motivational interviewing [28], one study employed trained community adolescent treatment supporters (CATS) to provide peer to peer support to YPLWH [31]. These techniques have proved to improve adherence and retention in care among YPLWH [22, 31]. Motivational interviewing is confirmed to help people adopt better health behaviours such as helping young people to use condoms more often, and also to reduce viral load [34]. Individual counselling interventions have also been identified as resource-intensive approaches [16] as they are applied at an individual level. Individual-focused counselling are labour-intensive and thus challenging to implement in low and middleincome countries (LMICs). However, equipping low cadre health care workers such as peer lay counsellors or CATS with the necessary skills could prove effective in providing ART care and support tailored to adolescent's particular needs [35].

Support groups were used in five of the interventions [27-29, 31, 32], whereby a space (physical and/or psychological) was created for participants to share knowledge, build social capital and expand their support systems. This method of delivering psychosocial support has been found to improve adherence, linkage to care and quality of life, thus constituting a viable treatment option in LMIC where healthcare staff and resources are limited [28]. Peer support has been reported as a major source of social support and information among adolescents in relation to living with HIV $[29,31]$. Furthermore, centralising health services for youth have the propensity to reduce barriers to retention and adherence to ART care by providing medical and social services at one central location and reducing the need for navigating complex healthcare systems and improving coordination of services. The enhanced centralised youth service programme attempted to reduce negative health beliefs and misinformation about HIV by supporting patients' emotional needs and providing youth friendly HIV education to address misconceptions about living with HIV $[28,30,31]$. Youth specific support groups and educational activities offer opportunities for young people to develop support systems, knowledge, and selfmanagement skills.

Family/household-centred services were found in two articles [27, 32], which enhanced family cohesion and communication in both cases. The family/householdcentred care approach argues that the family shares the responsibility of caring for the YPLWH [36]. A recent review conducted to explore the availability and effectiveness of family/household-focused interventions to improve ART adherence and retention in care found that some of the HIV-related interventions with a household focus were focused on YPLWH, and incorporated aspects of information sharing on HIV; improving communication; stimulating social support and promoting mental health [33]. Furthermore, studies have shown that integrating paediatric and adult services has positive outcomes on adherence and retention in care [37]. Additionally, the VUKA family programme addressed sensitive topics relating to HIV by using a culturally tailored cartoon [27]; such interactive modes of delivering interventions have been found to enable parent-child communication [38].

Appointment cards were used in one of the interventions where calendars and reminder cards helped schedule eligible patients to attend their next appointment on a family clinic day [32]. There is growing evidence from published literature that mHealth as a means of active client follow-up could improve the retention of patients in care through sending of SMS reminders of their appointment dates $[39,40]$. The World Health Organization recommend using mobile phone reminders to improve adherence, bearing in mind that the process should be carefully monitored when aimed at adolescents for effective implementation [41]. In addition, it 
has been argued that adherence interventions adopting a single approach, such as phone call reminders, are less effective compared to multicomponent interventions that mobilise several support strategies and delivery modalities [42], specifically due to lower cell phone network coverage in rural and remote areas in LMICs [43].

Our scoping review identified six studies that reported on the effects of psychosocial interventions on adolescent adherence to ART and retention in care. Despite the growing recognition of the burden of HIV and psychosocial challenges faced by YPLWH, this review indicates that there is a dearth of evidence on psychosocial support interventions aimed at YPLWH. Other authors have shared the same sentiments [44, 45]. Strasser et al. [44] state that evidence-based psychosocial support services for children are currently under-developed and under-resourced, and argue that the current state of affairs need to be addressed and improved. Petersen et al. [45] also identified the need for targeted efficacy-based mental health promotion interventions for children and adolescent HIV populations in South Africa.

Five studies in this review reported increased retention and adherence to ART among adolescents and young people following the administration of an intervention with psychosocial components [27, 28, 30-32]. A study evaluating the effects of a psychosocial intervention among PLHIV attending clinical care in Estonia reported that the intervention increased the proportion of patients that were optimally adherent [46]. Similarly, a study conducted by Tominari et al. [47] reported that the implementation of mental health services demonstrated a significant increase in retention in care among PLHIV.

Evidence suggests that ART adherence interventions need to adopt long-term and flexible approaches to effectively support adherence behaviour [42]. The study conducted by Wohl et al. [30] reported that a significant dose response trend was observed between retention in care and increasing number of hours in the intervention and increasing number of intervention appointments.

Furthermore, Wohl et al. [30] found that a timeintensive intervention delivered by a non-judgemental and culturally competent peer is effective in engaging participant in consistent ART care. These findings are supported by previous studies, which suggest that intensive interventions are required to produce effective adherence outcomes, while one-time interventions without ongoing educational support may prove inefficient [48]. According to Edwards and Barker [49], developing frameworks for understanding and describing contexts, which incorporate an adaptive approach for intervention implementation and scale-up are necessary to advance HIV/AIDS implementation research and to ensure the effectiveness of an intervention.
We learnt from the scoping review that psychosocial support interventions for YPLWH are feasible and acceptable to participants and healthcare workers. However, more empirical evidence is needed to understand the mechanisms which allow these interventions to work, to improve the availability of services and care for YPLWH. Limited information exists regarding the effectiveness of adherence interventions for YPLWH in LMICs [1]. The findings from the CATS and VUKA programme indicate that psychosocial interventions may be successfully implemented to improve YPLWH adherence to ART in resource limited settings. These findings are supported by a recent study reporting on the effectiveness of teen adherence clubs in Zimbabwe and South Africa [50].

\section{Limitations and strengths of the review}

A strength of this scoping review is our extensive and comprehensive database search that encompasses global peer reviewed papers with a narrative reporting approach. All questions related to inclusion/exclusion of a study were discussed with the investigating team. We observed significant heterogeneity in measurements and definition of optimal adherence and inclusion criteria for participants in the different studies.

The limitation of this scoping review and inference of results is limited by the quality of the individual papers underlying the process. For example, many of the papers included had small sample sizes. Further limitation to this scoping review is the exclusion of interventions that may have been evaluated using qualitative methods such as those conducted by Dorothy et al. [51], Donenberg et al. [52] and Mahvu et al. [53]. In addition, we only focused on English publications and those published after 2004 introducing the potential to have excluded studies that might have otherwise met these inclusion criteria. Our focus in the last 15 years was meant to capture the most recent evidence because so much has changed in the HIV/AIDS treatment and care protocol since its inception. Capturing the last 15 years would provide more relevant evidence regarding the most recent treatment care protocols. Furthermore, self-reported measures are fraught with bias compared to more objective measures of adherence such as viral load, antiretroviral drug levels and pill counts. Lastly, in this review, we did not differentiate the impact of behavioural patterns as a result of the intervention offered. For example, exploring the behavioural patterns between newly acquired HIV vs perinatal HIV. We also did not delineate the different age groups $10-19$ years and $20-24$ years as these age groups' psychosocial needs are different.

\section{Conclusion}

Individual and group counselling including familycentered group counselling and the use of adolescent 
peer support were distinctive treatment modalities when focusing on improving ART adherence, linkage to care and/or retention in care. However, this review found only six studies that evaluated psychosocial support interventions suggesting that there is dearth of evidence on psychosocial support interventions to improve adherence and retention in ART care amongst young people living with HIV. Where studies exist; methodological quality, target population, and sample size are limited. Future research and programming should seek to address psychosocial support interventions or approaches specifically designed to address the needs of YPLHIV.

\section{Appraisal of the study quality}

Methodological appraisal of study quality or risk of bias of the included articles, was based on the criteria provided by the NIH-NHLBI Quality Assessment of Systematic Reviews and Meta-Analyses assessment tool.

\section{Reporting}

The scoping review was reported following the PRISMA guidelines to enhance transparency in reporting.

\section{Supplementary Information}

Supplementary information accompanies this paper at https://doi.org/10. 1186/s12889-020-09717-y.

\section{Additional file 1.}

\section{Abbreviations}

ART: Antiretroviral therapy; HIV: Human Immunodeficiency-Virus; YPLHIV: Young people living with HIV; OLHIV: Older adults living with HIV; PICOT: Population, Intervention, Comparison, Outcome and Time; PRIS MA: Preferred Reporting Items for Systematic Reviews and Meta-Analyses

\section{Acknowledgements}

Not applicable because all contributors to this paper met the authorship criteria.

\section{Authors' contributions}

$E O, F C M$, and BVW designed the study and selected the search terms. SV and $\mathrm{ZO}$ screened titles and abstracts using the identified inclusion and exclusion criteria. The data were analysed by SV, ZO, EO and FCM. EO, SV and $\mathrm{ZO}$ drafted the first manuscript with editorial and content input from BWW and FCM. All authors read and approved the final manuscript.

\section{Authors' information}

The main author Emeka Okonji (EO) holds a master's degree in Demography and Population studies. He is currently working as senior monitoring and evaluation manager for an NGO that provides treatment care and support to people living with HIV and AIDS in South Africa. Furthermore, the author is currently doing his PhD in the field of Public Health. This paper is part of his PhD programme and aim to make a case for a psychosocial intervention specifically designed to improve adherence and retention amongst adolescents living with HIV and AIDS.

\section{Funding}

No funding was received for this study.

\section{Availability of data and materials}

Because the study was a scoping review of published studies, the full references of these studies have been provided in the reference list.
Ethics approval and consent to participate

Not applicable.

Consent for publication

Not applicable.

\section{Competing interests}

The authors declare no competing interests.

Received: 24 April 2020 Accepted: 15 October 2020

Published online: 01 December 2020

\section{References}

1. Hudelson C, Cluver L. Factors associated with adherence to antiretroviral therapy among adolescents living with HIV/AIDS in low- and middleincome countries: a systematic review. AIDS Care 2015;27:805-816. https:// doi.org/10.1080/09540121.2015.1011073.

2. Mukumbang FC, Van Belle S, Marchal B, Van Wyk B. Exploring "generative mechanisms" of the antiretroviral adherence club intervention using the realist approach: a scoping review of research-based antiretroviral treatment adherence theories. BMC Public Health 2017:17:1-14. https://doi.org/10. 1186/s12889-017-4322-8

3. Mutumba M, Musiime V, Lepkwoski JM, Harper GW, Snow RC, Resnicow K, et al. Examining the relationship between psychological distress and adherence to anti-retroviral therapy among Ugandan adolescents living with HIV. AIDS Care 2016;28:807. https:/www.tandfonline.com/doi/full/ https://doi.org/10.1080/09540121.2015.1131966.

4. Wong VJ, Murray KR, Phelps BR, Vermund SH, Mccarraher DR. Adolescents, young people, and the 90-90-90 goals: a call to improve HIV testing and linkage to treatment. AIDS. 2017;191-194. https://doi.org/10.1097/QAD. 0000000000001539. Accessed 24 Apr 2018.

5. UNICEF: Turning the tide against AIDS will require more concentrated focus on adolescents and young people. 2018. https://data.unicef.org/topic/ hivaids/adolescents-young-people/. Accessed 24 Sept 2018.

6. UNAIDS 2019 estimates. https://www.unaids.org/en/resources/documents/2 019/2019-UNAIDS-data. Accessed 27 Feb 2020

7. Dow D, Turner E, Shavo A, Mmbaga B, Cunningham C, O'Donnell K. Evaluating mental health and associated difficulties among HIV positive adolescents in Tanzania. AIDS Care 2016;28:825-833. https://doi.org/10.1080/ 09540121.2016.1139043.

8. Sam-Agudu NA, Pharr JR, Bruno T, Cross CL, Cornelius LJ, Okonkwo P, et al. Adolescent coordinated transition (ACT) to improve health outcomes among young people living with HIV in Nigeria: study protocol for a randomized controlled trial. Trials. 2017;18:1-12. https://doi.org/10.1186/ s13063-017-2347-z.

9. Aderemi TJ, Mac-seing M, Woreta SA, Agbemavi K. Predictors of voluntary HIV counselling and testing services utilization among people with disabilities in Addis Ababa, Ethiopia. AIDS Care. 2014. https://doi.org/10. 1080/09540121.2014.923811.

10. Sibhatu B, Amare D, Amberbir A, Kebede D. Barriers and facilitators to antiretroviral medication adherence among HIV-infected paediatric patients in Ethiopia : a qualitative study. SAHARA J. 2009. https://doi.org/10.1080/ 17290376.2009.9724943 Accessed 15 Jun 2018.

11. Vreeman RC, McCoy BM, Lee S. Mental health challenges among adolescents living with HIV. J Int AIDS Soc https://doi.org/10.7448/IAS.20.4 21497.

12. Woollett N, Cluver L, Bandeira M, Brahmbhatt H. Identifying risks for mental health problems in HIV positive adolescents accessing HIV treatment in Johannesburg. J Child Adolesc Ment Health 2017;29:11-26. https://doi.org/ 10.2989/17280583.2017.1283320

13. Naidoo K, Munsami A, Archary M. Adolescent antiretroviral management: Understanding the complexity of non-adherence. S Afr Med J. 2015:105:953. https://doi.org/10.7196/SAMJ.2015.v105i11.10150.

14. Lowenthal ED, Bakeera-kitaka S, Marukutira T, Chapman J, Goldrath K, Ferrand RA, et al. Perinatally acquired HIV infection in adolescents from subSaharan Africa: a review of emerging challenges Lancet Infect Dis 2014;14: 627-639. https://doi.org/10.1016/\$14733099(13)70363-3.

15. Greifinger R \& Dick B. Provision of psychosocial support for young people living with HIV: voices from the field. SAHARA J 2011:8:33-41. https://doi. org/10.1080/17290376.2011.9724982. 
16. MacPherson P, Munthali C, Ferguson J, Armstrong A, Kranzer K, Ferrand RA, et al. Service delivery interventions to improve adolescents' linkage, retention and adherence to antiretroviral therapy and HIV care. Trop Med Int Health 2015;8:1015-1032. https://doi.org/ 10.1111/tmi.12517.

17. Sanchez-Sosa JJ. Treatment adherence: The role of behavioral mechanisms and some implications for health care interventions. Rev Mex Psicol. http:// www.healthnet.unam.mx 2002;19:85-92. Accessed 16 Jun 2018.

18. England MJ, Butler AS, Gonzalez ML. Psychosocial interventions for mental and substance use disorders: a framework for establishing evidence-based standards. Washington (DC): National Academies Press (US); 2015. https://www.ncbi.nlm.nih.gov/books/NBK305126/; https://doi org/10.17226/19013.

19. Schotanus-dijkstra M, Drossaert CHC, Pieterse ME, Boon B, Walburg JA, Bohlmeijer ET. An early intervention to promote well-being and flourishing and reduce anxiety and depression : a randomized controlled trial. Internet Interv. 2017;9:15-24 https://doi.org/10.1016/j.invent.2017.04.002.

20. WHO. A qualitative review of psychosocial support interventions for young people living with HIV. 2009 https://www.who.int/maternal_ child_adolescent/documents/who_fch_cah_adh_09_05/en/. Accessed 10 Aug 2018.

21. Spaan, P, Luenen, S, Ganesfski, N, Kraaiji V. Psychosocial interventions enhance HIV medication adherence: a systematic review and meta-analysis. J Health Psychol 2018;1-15. https://doi.org/10.1177/1359105318755545.

22. Bofill L, Weiss SM, Lucas M, Bordato A, Dorigo A, Fernandez-Cabanillas G, et al. Motivational Interviewing among HIV Health Care Providers: Challenges and Opportunities to Enhance Engagement and Retention in Care in Buenos Aires, Argentina. J Int Assoc Provid AIDS Care 2015;14:491496. https://doi.org/10.1177/2325957415586257. NIH Public.

23. Sherr L. Mental health—a bridge not so far. Lancet Glob Health. 2017;5: e559-60 https://doi.org/10/1016/S2214-109X(17)30183-3.

24. Khan KS, Kunz R, Kleijnen J, Antes G. Five steps to conducting a systematic review. J R Soc Med. 2003;96:118-21.

25. NIH-NHLBI Quality Assessment of Systematic Reviews and Meta-Analyses assessment tool: https://www.nhlbi.nih.gov/health-topics/study-qualityassessment-tools. Accessed 10 Aug 2018.

26. Snilstveit B, Oliver S, Vojtkova M. Narrative approaches to systematic review and synthesis of evidence for international development policy and practice. J Dev Eff 2012;4:409-429. https://doi.org/10.1080/19439342.2012. 710641.

27. Bhana A, Mellins CA, Petersen I, Alicea S, Myeza N, Holst H, et al. The VUKA family program: piloting a family-based psychosocial intervention to promote health and mental health among HIV infected early adolescents in South Africa. AIDS Care 2014;26:1-11. https://doi.org/10.1080/09540121. 2013.806770.

28. Davila JA, Miertschin N, Sansgiry S, Schwarzwald H, Henley C, Giordano TP. Centralization of HIV services in HIV-positive African-American and Hispanic youth improves retention in care. AIDS Care; 2013;25:202-206. https://doi. org/10.1080/09540121.2012.689811.

29. Ruria EC, Masaba R, Kose J, Woelk G, Mwangi E, Matu L, et al. Optimizing linkage to care and initiation and retention on treatment of adolescents with newly diagnosed HIV infection. AIDS. 2017;31:S253-S260. https://doi. org/10.1097/QAD.0000000000001538.

30. Wohl AR, Garland WH, Wu J, Au CW, Boger A, Dierst-Davies R, et al. A youth-focused case management intervention to engage and retain young gay men of color in HIV care. AIDS Care 2011;23:988-997. https://doi.org/10. 1080/09540121.2010.542125.

31. Willis N, Milanzi A, Mawodzeke M, Dziwa C, Armstrong A, Yekeye I, Mtshali $P$, James $V$. Effectiveness of community adolescent treatment supporters (CATS) interventions in improving linkage and retention in care, adherence to ART and psychosocial well-being: a randomised trial among adolescents living with HIV in rural Zimbabwe. BMC Public Health. 2019;19:1-9.

32. Graves JC, Elyanu P, Schellack CJ, Asire B, Prust ML, Prescott MR, et al. Impact of a family clinic day intervention on paediatric and adolescent appointment adherence and retention in antiretroviral therapy: a cluster randomized controlled trial in Uganda. PLoS One 2018;13:1-18. https://doi. org/10.1371/journal.pone.0192068.

33. Mukumbang, F.C., Knight, L., Masquillier, C. et al. Household-focused interventions to enhance the treatment and management of HIV in lowand middle-income countries: a scoping review. BMC Public Health 19, 1682 (2019). https://doi.org/10.1186/s12889-019-8020-6.
34. Mbuagbaw L, Ye C, Thabane L. Motivational interviewing for improving outcomes in youth living with HIV. Cochrane Database Syst Rev 2012, Issue 9. Art. No.: CD009748. https://doi.org/10.1002/14651858.CD009748.pub2.

35. Mary Fabri, Charles Ingabire, Mardge Cohen, Geri Donenberg, Sabin Nsanzimana. The mental health of HIV-positive adolescents. 2015; https:// doi.org/10.1016/S2215-0366(15)00291-6.

36. Belsey MA. AIDS and the family: policy options for a crisis in family capital. Doha, Qatar: UNAIDS; 2005. https://www.un.org/esa/socdev/family/ Publications/aidsandthefamily.pdf. Accessed 18 Mar 2018.

37. Leeper SC, Montague BT, Friedman JF, Flanigan TP. Lessons learned from family-centred models of treatment for children living with HIV: current approaches and future directions. J Int AIDS Soc 2010;13(Suppl 2):S3. https://doi.org/10.1186/1758-2652-13-S2-S3.

38. Bastien S, Kajula $\amalg$, Muhwezi WW. A review of studies of parent-child communication about sexuality and HIV/AIDS in sub-Saharan Africa. Reprod Health 2011;8:25. https://doi.org/10.1186/1742-4755-8-25.

39. Puccio JA, Belzer M, Olson J, Martinez M, Salata C, Tucker D, et al. The use of cell phone reminder calls for assisting HIV-infected adolescents and young adults to adhere to highly active antiretroviral therapy: a pilot study. AIDS Patient Care STDs 2006;20:438-444. https://doi.org/10.1089/apc.2006.20.438.

40. Haberer JE et al. Improving antiretroviral therapy adherence in resourcelimited settings at scale: a discussion of interventions and recommendations. J Int AIDS Soc 2017, 20:21371. http://www.jiasociety.org/ index.php/jias/article/view/21371. https://doi.org/10.7448/IAS.20.1.21371.

41. World Health Organization. HIV and Adolescents: Guidance for HIV Testing and Counselling and Care for Adolescents Living with HIV. Recommendations for a Public Health Approach and Considerations for Policy-Makers and Managers, vol. 100. Geneva: WHO Publ; 2013. https:// apps.who.int/iris/handle/10665/94334. Accessed 20 Mar 2018.

42. Simoni JM, Amico KR, Smith L, Nelson K. Antiretroviral adherence interventions: translating findings to the real world clinic. Curr HIV/AIDS Rep 2010;7:44-51. https://doi.org/10.1007/s11904-009-0037-5.

43. Casale M, Carlqvist A, Cluver L. Recent interventions to improve retention in HIV care and adherence to antiretroviral treatment among adolescents and youth: A systematic review. AIDS Patient Care STDs. 2019;33:6. https://doi. org/10.1089/apc.2018.0320.

44. Strasser S, Gibbons S. The development of HIV-related mental health and psychosocial services for children and adolescents in Zambia: the case for learning by doing. Child Youth Serv Rev 2014;45:150-157. https://doi.org/10. 1016/j.childyouth.2014.03.032.

45. Petersen I, Bhana A, Myeza N, Alicea S, John S, Holst H, Mckay M, Mellins C. Psychosocial challenges and protective influences for socio- emotional coping of HIV+ adolescents in South Africa. A qualitative investigation. https://doi.org/10.1080/09540121003623693.

46. Uusküla A, Laisaar K-T, Raag M, Lemsalu L, Lõhmus L, Rüütel K, et al. Effects of Counselling on adherence to antiretroviral treatment among people with HIV in Estonia: a randomized controlled trial. AIDS Behav 2018;22:224-233. https://doi.org/10.1007/s10461-017-1859-6.

47. Tominari S, Nakakura T, Yasuo T, Yamanaka K, Takahashi Y, Shirasaka T, et al. Implementation of mental health service has an impact on retention in HIV care: a nested case-control study in a japanese HIV care facility. PLoS One 2013;8:e69603. https://doi.org/10.1371/journal.pone.0069603.

48. Simoni JM, Amico KR, Pearson CR, Malow R. Strategies for promoting adherence to antiretroviral therapy: a review of the literature. Curr Infect Dis Rep 2008;10:515-521. https://doi.org/10.1007/s11908-008-0083-y.

49. Edwards N, Barker PM. The importance of context in implementation research. J Acquir Immune Defic Syndr 2014;67(Suppl 2):S157-S162. https:// doi.org/10.1097/QAl.0000000000000322.

50. MacKenzie RK, van Lettow M, Gondwe C, Nyirongo J, Singano V, Banda V, et al. Greater retention in care among adolescents on antiretroviral treatment accessing "teen Club" an adolescent-centred differentiated care model compared with standard of care: a nested case-control study at a tertiary referral hospital in Malawi. J Int AIDS Soc 2017;20. https://doi.org/10. 1002/jia2.25028.

51. Dow DE, Mmbaga BT, Turner EL, Gallis JA, Tabb ZJ, Cunningham CK, O'Donnell KE. Building resilience: a mental health intervention for Tanzanian youth living with HIV. AIDS Care. 2018;30(sup4):12-20. https://doi.org/10. 1080/09540121.2018.1527008.

52. Donenberg GR, Cohen MH, Ingabire C, et al. Applying the Exploration Preparation Implementation Sustainment (EPIS) Framework to the Kigali Imbereheza Project for Rwandan Adolescents Living With HIV. J Acquir 
Immune Defic Syndr. 2019;82(Suppl 3):S289-98. https://doi.org/10.1097/QAl. 0000000000002204.

53. Mavhu W, Willis N, Mufuka J, et al. Effect of a differentiated service delivery model on virological failure in adolescents with HIV in Zimbabwe (Zvandiri): a cluster-randomised controlled trial. Lancet Glob Health. 2020;8(2):e264-75. https://doi.org/10.1016/S2214-109X(19)30526-1.

\section{Publisher's Note}

Springer Nature remains neutral with regard to jurisdictional claims in published maps and institutional affiliations.

Ready to submit your research? Choose BMC and benefit from:

- fast, convenient online submission

- thorough peer review by experienced researchers in your field

- rapid publication on acceptance

- support for research data, including large and complex data types

- gold Open Access which fosters wider collaboration and increased citations

- maximum visibility for your research: over $100 \mathrm{M}$ website views per year

At $\mathrm{BMC}$, research is always in progress.

Learn more biomedcentral.com/submissions 